\title{
IMPACTOS DA PANDEMIA DE COVID-19 NAS INSTITUIÇÕES AMBIENTAIS DE CARAVELAS, BAHIA: EFEITOS ASSOCIADOS AO PERÍODO DE ISOLAMENTO SOCIAL
}

\section{ARTIGO ORIGINAL}

PORTELA, Ellen Maria Santos ${ }^{1}$, SILVA, Ingrid Melissa Noberto da ${ }^{2}$, SANTOS, Joana Farias dos $^{3}$

PORTELA, Ellen Maria Santos. SILVA, Ingrid Melissa Noberto da. SANTOS, Joana Farias dos. Impactos da pandemia de Covid-19 nas instituições ambientais de caravelas, Bahia: efeitos associados ao período de isolamento social. Revista Científica Multidisciplinar Núcleo do Conhecimento. Ano 06, Ed. 09, Vol. 02, pp. 6680. Setembro de 2021. ISSN: 2448-0959, Link de acesso: https://www.nucleodoconhecimento.com.br/meio-ambiente/instituicoes-ambientais, DOI: 10.32749/nucleodoconhecimento.com.br/meio-ambiente/instituicoes-ambientais

\section{RESUMO}

Este artigo teve como objetivo analisar os impactos e desafios impostos pela pandemia da COVID-19 no desempenho das atividades e ações das Unidades de Conservação (UC's) e Organizações Não Governamentais (ONG's) que atuam na conservação e preservação do meio ambiente na cidade de Caravelas, Bahia. A pesquisa se deu em função da necessidade da análise e compreensão de como essas instituições e seus profissionais estão conduzindo seus trabalhos durante esse período pandêmico e quais seriam as maiores dificuldades enfrentadas do ponto de vista ambiental. Como instrumento principal, foi utilizado a plataforma Google Forms para o envio do questionário. Participaram desta pesquisa 07 instituições. As instituições foram abordadas com um questionário qualiquantitativo,

\footnotetext{
${ }^{1}$ Graduanda em Ciências Biológicas (Licenciatura).

2 Bacharelado Interdisciplinar em Ciências.

${ }^{3}$ Pós-doutorado pela Universidade Federal do Espírito Santo.
}

RC: 96564

Disponível em: https://www.nucleodoconhecimento.com.br/meioambiente/instituicoes-ambientais 
acerca das dificuldades de manter o funcionamento dessas mesmas instituições em período pandêmico e entender as limitações e os impactos que a pandemia do novo coronavírus (SARS-Cov-2) trouxe e de que forma as instituições puderam se inovar nesse momento. Portanto, em relação aos problemas ambientais, $28 \%$ dos respondentes acreditam que houve impactos negativos, $28 \%$ responderam que ainda é cedo para afirmar sobre o agravamento e $44 \%$ relataram que a pandemia não agravou os problemas, apenas os mantiveram. Todavia, verificou-se que em decorrência da pandemia, houve desemprego, fechamento de escritório, atividades de campo paralisadas e cancelamento de eventos. Evidencia-se a necessidade de acompanhamento contínuo nas UC's e ONG's ambientalistas de Caravelas, no contexto de transição do remoto para a volta ao presencial, com adoção de estratégias de construção participativa entre o terceiro setor, setor público e sociedade civil.

Palavras-Chave: SARS-Cov-2, Unidades de Conservação, Organizações Não Governamentais.

\section{INTRODUÇÃO}

O mundo se transformou em decorrência da pandemia ocasionada pela infecção respiratória aguda grave provocada pelo novo coronavírus (SARS-CoV-2), causador da doença COVID-19 (ANVISA, 2020). Em dezembro de 2020 os primeiros casos foram diagnosticados em Wuhan, província de Hubei, República Popular da China, onde os primeiros pacientes apresentaram infecções no trato respiratório, tais pacientes viviam em torno do mercado atacadista de frutos do mar ou trabalhavam no local (CHENE et al., 2020).

Em janeiro de 2020, novos casos da COVID-19 foram notificados fora da China. $\mathrm{Na}$ América Latina, o primeiro caso registrado foi em São Paulo, no Brasil, no dia 26 de fevereiro de 2020 (BEZZERA et al., 2020). A rápida propagação da referida infecção em todo o mundo, levou a Organização Mundial da Saúde (OMS) a declarar em 11 
de março de 2020, a infecção COVID-19 em pandemia mundial (BECHING; FLETCHER; ROBERT, 2020).

O primeiro caso importado do novo coronavírus (COVID-19) no Estado da Bahia (BA) foi em 06 de março de 2020, na cidade baiana de Feira de Santana (SESAB, 2020) e o primeiro caso de COVID-19 confirmado na cidade de Caravelas, BA ocorreu em 30 de maio de 2020 (PREFEITURA MUNICIPAL DE CARAVELAS, 2020).

Atualmente já foram registrados no mundo mais de 136.286.922 milhões de casos e 2.938.658 milhões de mortes, no Brasil foram confirmados 13.487 .909 casos e 353.411 mortes pela COVID-19 (DASA ANALYTICS, 2021). Na Bahia desde início da pandemia, foram confirmados 840.976 casos e 16.611 (SESAB, 2021), já em Caravelas foram 1.058 confirmados, somando 11 óbitos (PREFEITURA MUNICIPAL DE CARAVELAS, 2021).

Segundo Bezzera, et al., (2020), após a chegada da COVID-19 no Brasil, diversas medidas de controle e prevenção da doença foram tomadas pelas autoridades sanitárias locais em diferentes esferas administrativas (governo federal, governos estaduais e municipais). Essas medidas se diferenciaram de uma região para outra do país, entretanto a medida mais difundida pelas autoridades foi a prática do distanciamento social, recomendada pela OMS como método mais eficaz na prevenção à pandemia.

Essa pandemia representa um dos maiores desafios sanitários dos últimos 100 anos (BRITO et al., 2020), gerando impactos em todos os setores sociais. O Brasil atravessa um momento de crise na ciência, cortes nas pesquisas, falta de investimento em áreas da saúde e educação, amplificando a dificuldade de enfrentamento do vírus (HENRIQUES E VASCONCELOS, 2020).

Werneck e Carvalho (2020), ressaltam que a COVID-19 provoca um grande choque na sociedade brasileira em todos os setores, ela passa por um momento de vulnerabilidade extrema, com escassez de emprego e cortes de verbas nas políticas

RC: 96564

Disponível em: https://www.nucleodoconhecimento.com.br/meioambiente/instituicoes-ambientais 
públicas. A quarentena não só torna mais visíveis, como reforça a injustiça, a discriminação, a exclusão social e o sofrimento imerecido que elas provocam (SANTOS, 2020).

Com esse cenário, o meio ambiente na época de COVID-19, sofreu impactos tanto positivos quanto negativos. Com as medidas de isolamento social, diminuição do tráfego de automóveis e pausa nas atividades de algumas indústrias, nota-se mudanças significativas na qualidade do ar e redução de rejeitos industriais. Por outro lado, teve-se aumento em longa escala de plásticos, matérias hospitalares, e outros resíduos de uso comum que estão sendo descartados de maneira inapropriada no meio ambiente, gerando sérias consequências para fauna e flora (SOUZA, 2020).

Segundo Maia et al., (2020), alguns animais podem se beneficiar de forma mais imediata, como aves voltando a nidificar em certas áreas ou peixes reocupando canais outrora poluídos, mas mesmo a natureza dando mostras de reparos, isso não significa dizer que esteja se recuperando.

Segundo o IBGE (2017), a economia da cidade de Caravelas gira em torno do serviço público, turismo e pesca artesanal. Estes dois últimos setores foram os mais afetados pela pandemia da COVID-19, com o isolamento social as portas da cidade foram fechadas para os turistas, a venda de pescados e agricultura caíram, os indivíduos tiveram que se reinventar, passando pela crise com formas alternativas para geração de renda (SULBAHIA NEWS, 2021.)

possui uma grande biodiversidade, abrigando espécies endêmicas na sua fauna e flora. Em favor da preservação ambiental estão presentes quatro Unidades de Conservação (UC's) na cidade. Além de Organizações Não Governamentais (ONG's) que trabalham diretamente em favor do meio ambiente, realizando trabalhos de Educação Ambiental (EA), oficinas, limpezas das praias, dentre outras ações. 
A redução das atividades e 0 isolamento social provocado pela pandemia da COVID-19 podem ter ocasionado alguns impactos nas UC's e ONG's que atuam em Caravelas BA, havendo a necessidade da análise e compreensão de como essas Instituições e seus profissionais estão conduzindo seus trabalhos durante esse período pandêmico e quais seriam as maiores dificuldades enfrentadas do ponto de vista ambiental, destacando as medidas que foram adotadas para dar segmentos as suas atividades. Para tanto, o presente estudo emergiu em um questionamento que norteou o desenvolvimento do mesmo, a saber: Quais são os impactos e desafios da COVID-19 na área ambiental em Caravelas - BA?

Nesse sentido, o presente artigo teve como objetivo analisar os impactos e desafios impostos pela pandemia da COVID-19 no desempenho das atividades e ações das UC's e ONG's que atuam na conservação e preservação do meio ambiente na cidade de Caravelas, Bahia.

\section{MATERIAL E MÉTODO}

\section{1 ÁREA DE ESTUDOS}

O presente estudo foi realizado no município de Caravelas, localizado na Região Extremo Sul da Bahia (Figura 1). Possui uma área territorial de $2.377,889 \mathrm{~km}^{2} \mathrm{e}$ estimativa de 22.093 pessoas na sua população (IBGE, 2017).

Caravelas possui uma biodiversidade ampla com uma área de preservação de 346.535 hectares que compõe a Área de Preservação Permanente (APA) da Ponta da Baleia/Abrolhos (Figura 2), que liga o município de Caravelas ao de Prado, Alcobaça e Nova Viçosa (INEMA, 1993). 
Figura 1 - Mapa da Bahia, com destaque para a Região Extremo Sul e para o Município de Caravelas - Bahia.

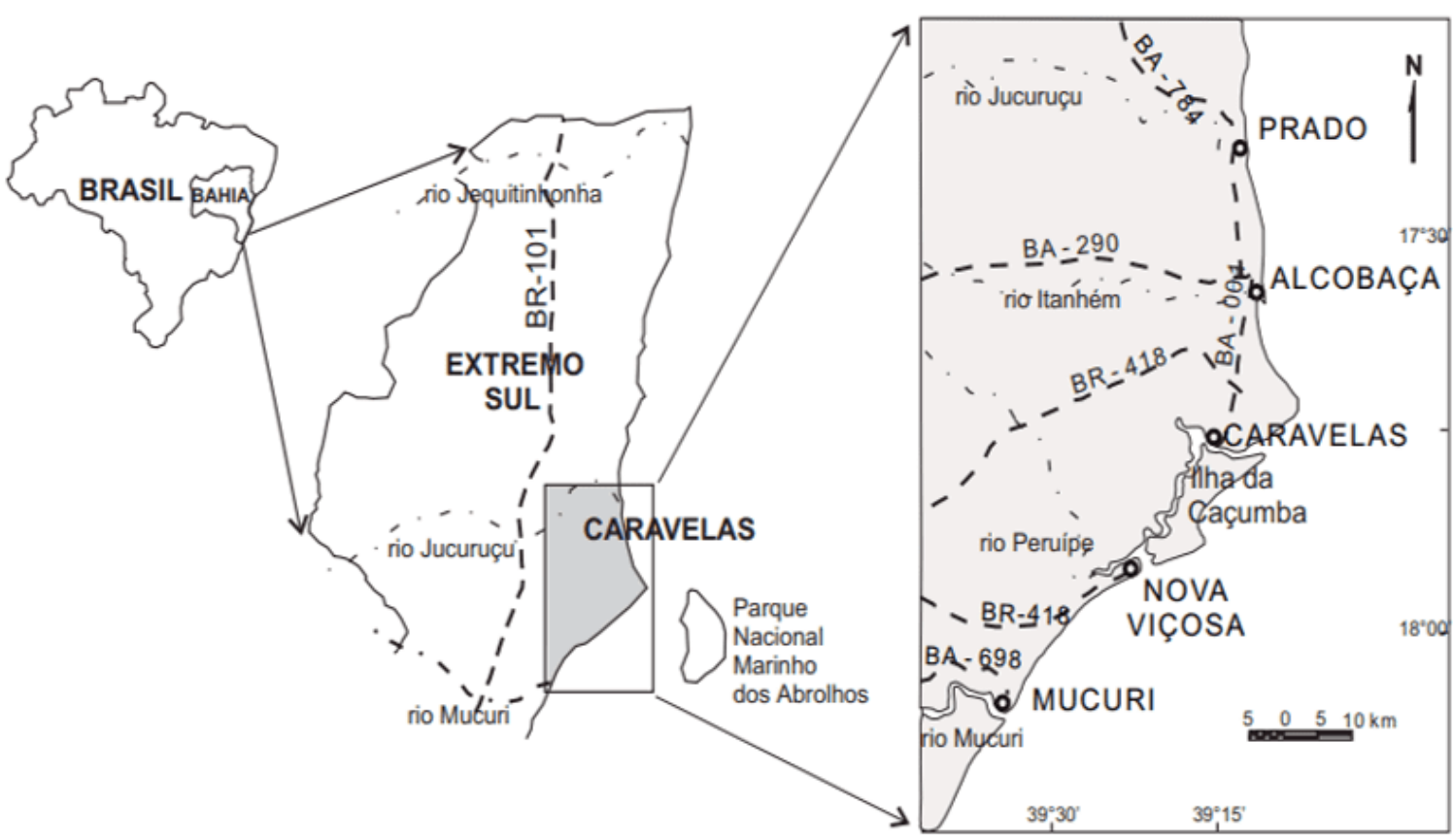

Fonte: ANDRADE; DOMINGUEZ, 2002.

RC: 96564

Disponível em: https://www.nucleodoconhecimento.com.br/meioambiente/instituicoes-ambientais 
Figura 2 - Imagem do Município de Caravelas, BA com destaque para a APA Ponta da Baleia/Abrolhos.

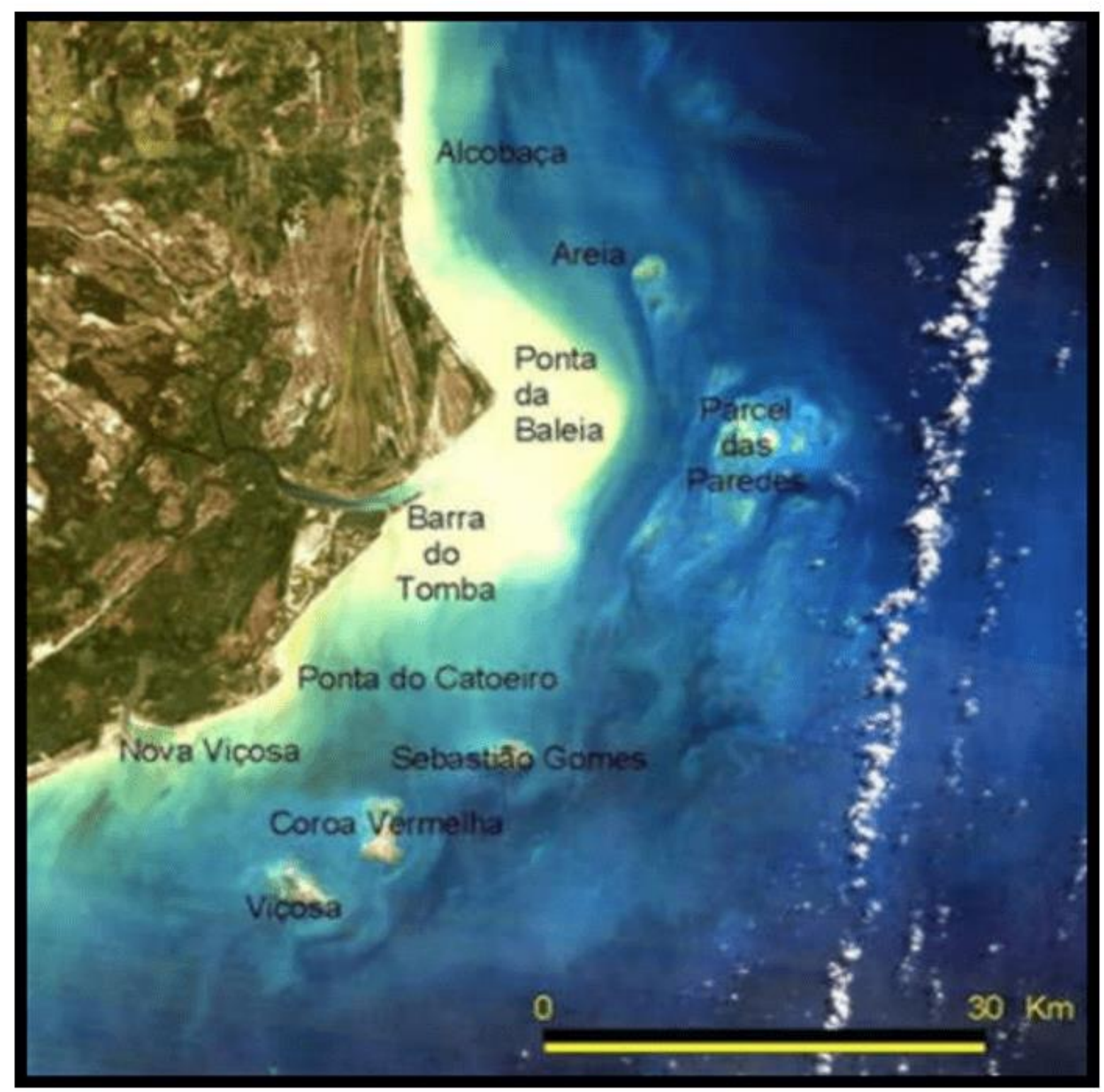

Fonte: DUTRA, 2003.

\subsection{PROCEDIMENTOS METODOLÓGICOS}

A metodologia aplicada permite um diálogo expressivo onde os indivíduos expressam suas opiniões, gerando um exercício reflexivo em suas falas.

RC: 96564

Disponível em: https://www.nucleodoconhecimento.com.br/meioambiente/instituicoes-ambientais 
A pesquisa foi realizada com as UC's e ONG's ambientalistas que atuam no município de Caravelas, BA. Trata-se de um estudo descritivo (GIL, 2002) de corte transversal (FONSECA, 2002).

Segundo Marques (2020), em Caravelas existem as seguintes UCs: Áreas de Proteção Ambiental (APA) Ponta da Baleia/Abrolhos, Reserva Extrativista do Cassurubá (RESEX), Parque Nacional Marinho dos Abrolhos (PARNA MAR Abrolhos) e o Parque Natural Municipal Maria e Amélio Siquara. E os seguintes seguimentosde Organizações de cunho ambiental em atuação: Associações de Pescadores, Associações de Produtores Rurais, Aldeia de Aprendizagem Guaiamum Curioso, Instituto Baleia Jubarte, Patrulha Ecológica - Escola da Vida e Conservation International do Brasil.

O processo de amostragem iniciou-se com um questionário virtual, gerado por meio de uma ferramenta gratuita oferecida pelo Google: o Google Forms, contendo 14 questões, 10 discursivas e 4 objetivas. Disponibilizado através dos e-mails corporativos, a participação foi voluntária, sem nenhum custo aos envolvidos. A coleta de dados aconteceu entre os dias 15 de dezembro (2020) a 05 de janeiro (2021), após o consentimento dos participantes.

Ao final do processo, as respostas obtidas foram contadas e tabuladas no Excel Office para a extração de gráficos.

\section{RESULTADOS E DISCUSSÕES}

Participaram desta pesquisa 07 instituições: Reserva Extrativista do Cassurubá, Parque Municipal Amélio Siquara, Associação de Moradores e Pescadores da Barra de Caravelas, Escola Guaiamum Curioso, Instituto Baleia Jubarte, Patrulha Ecológica e a Conservação Internacional - $\mathrm{Cl}$ Brasil. Vale aqui ressaltar que o questionário foi enviado para 12 instituições, mas apenas 07 aceitaram responder. 
A partir das respostas obtidas pelo formulário eletrônico foi possível delinear graficamente os objetivos explicitados nesta pesquisa e para uma melhor compreensão foram sistematizados conforme será demonstrado a seguir.

Os respondentes variam de coordenador de projetos a presidente institucional. Sobre o nível de escolaridade, a pesquisa não pretendia atingir nenhum segmento intelectual e social em específico, entretanto os dados revelaram que os respondentes variaram de indivíduos com curso técnico a superior completo, e alguns com mestrado. A quantidade de funcionários que trabalham nas instituições pesquisadas variou entre 01 e 26 pessoas, tendo uma média de 09 funcionários.

Quanto às respostas à questão, quais trabalhos/ações desenvolvidos pela instituição em Caravelas? Ficou evidente que, as instituições em geral desenvolvem trabalhos e ações de cunho socioambiental na cidade de Caravelas, sendo citadas: conservação de Baleias Jubartes (Megaptera novaeangliae), gestão das UC's PARNAM Abrolhos e RESEX de Cassurubá, vistoria e fiscalização ambiental, educação ambiental, apoio aos pescadores, educação socioambiental, arteeducação, educomunicação, projetos e apoios em geral para fortalecimento das UCs, limpeza de praia, oficinas, entre outros.

Quais foram as mudanças que o isolamento social e a pandemia COVID-19 afetou no dia a dia da instituição? Tal questão buscou conhecer quais mudanças provocadas pelo isolamento no dia a dia das instituições pesquisadas, diante as respostas destaca-se: início do trabalho a distância, dificuldade na elaboração de políticas públicas, suspensão das visitas ao campo, suspensão de eventos regionais, nacionais e internacionais, suspensão de estagiários, redução da equipe científica, fechamento de alguns escritores. Todavia, algumas ações foram repensadas para acontecer de maneiras diferenciadas, surgiram Lives com temáticas variadas, reuniões e até festas totalmente online.

Apesar dessa conjuntura, a pandemia nos mostrou que é possível desenvolvermos ações em casa, com o trabalho remoto, algumas pessoas se sentem mais à vontade 
e produtivas desenvolvendo ofícios fora de um escritório, diminuindo o estresse de deslocamento casa versus trabalho, aumentando rendimento financeiro, visto que evita gastos com transporte e refeição, sendo assim, Guenther (2020), destaca que o trabalho remoto não impactou negativamente nas condições socioeconômicas dos trabalhadores.

Todavia, Braz (2020) salienta o lado sombrio do isolamento social e da ocupação remota, enunciando que perante a crise, o funcionário perpetua no misto de suas emoções, aumentando o nível de cobrança para uma alta produção, mantendo-se produtivo a todo tempo mesmo diante da emergência global, gerando um vazio, ansiedade frustrações.

Salienta-se que, uma das instituições pesquisadas disse que não sabe se continuará com as atividades em Caravelas, por conta da instabilidade financeira. E outra relatou que alguns colaboradores desenvolveram transtornos psicológicos e estão recebendo auxílio psiquiátrico ou psicológico, mas não pode afirmar que isso decorre por conta do isolamento social.

Questionadas se as atividades desenvolvidas pela instituição foram interrompidas durante a chegada da pandemia COVID-19 na Bahia. Todas as instituições pesquisadas os respondentes disseram que as atividades foram interrompidas durante a pandemia, a saber: suspensão de atividades presenciais, atendimento ao público, suspensão de visitas presenciais, evento que geraria aglomeração e deslocamento de pessoas e encontros foram cancelados. Somente uma das instituições pesquisadas desenvolveu apenas uma atividade durante a pandemia, por ter sido agraciada com um Edital de Auxílio Emergencial, tal instituição distribuiu 150 kits de arte para famílias das comunidades de Tapera Morungaba, Barra de Caravelas e Portelinha com objetivo de complementar renda destas famílias.

Sobre a realidade do Home Officie, Brunetti (2020, p. 5), realça que:

A maioria das empresas tiveram menos de uma semana para colocar todos ou a grande maioria dos seus funcionários dentro do universo home office, 
foi uma corrida contra o tempo para comprar ou alugar computadores e ainda arranjar tempo para mudar a cultura de trabalho, as famosas reuniões de feedback, follow-up, encontros gerencias, apresentação de fornecedores, workshops teriam que se reinventar e várias ferramentas de apoio diários aos usuários.

Quando questionado se na visão da instituição a pandemia COVID-19 pode ter trazido agravamento dos problemas ambientais já existentes no município de Caravelas? Se positivo, cite tais problemas. No universo amostrado, $28 \%$ acreditam que ainda é cedo para afirmar que a pandemia agravou os problemas ambientais da cidade, relatam ainda que alguns impactos negativos foram diminuídos, havendo aumento das discussões e debates ambientais por meio de reuniões online, a Prefeitura Municipal de Caravelas Implementou a coleta seletiva no município, houve redução considerável do número de embarcações navegando na região. Assim, as Baleias Jubartes puderam se reproduzir com o mar menos movimentado, com isso também foram minimizados os riscos de acidentes e pôde-se registrar muitos filhotes nascidos nas águas de Caravelas nessa temporada 2020.

Para $28 \%$ dos respondentes a pandemia trouxe agravantes para o meio ambiente, alegando que houve suspensão em atividades, como limpezas de praia e a suspensão de fiscalização no território. Enquanto 44\% das instituições acreditam que a pandemia não agravou os problemas ambientais do município, apenas mantiveram alguns impactos já decorrentes, como por exemplo a sobrepesca.

Além dos impactos relatados acima na cidade de Caravelas, podemos notar outros a nível global, de acordo com Oliveira, Campos e Siqueira (2020), a redução das emissões de gases atmosféricos, atenuação da geração de $\mathrm{CO}^{2}$ e redução na geração de resíduos, são alguns dos efeitos positivos acarretado pela pandemia no meio ambiente.

Souza (2020) afirma que a pandemia da COVID-19 veio como um sinal vermelho para a população, segundo o autor, a natureza já demonstra há longos períodos os impactos negativos que vem sofrendo, produções exploratórias sobre a fauna e flora, exploração sem limite dos recursos naturais, dentre outras ações antrópicas. 
A pergunta, em que escala a pandemia COVID-19 atingiu as ações/funcionamento da instituição, buscou avaliar qual o grau de escala em que a pandemia atingiu diretamente a instituição. Em resposta, as 07 instituições participantes da pesquisa, $03(42,9 \%)$ foram afetadas em grande escala, $03(42,9 \%)$ das instituições foram afetadas em mínima escala e 01 (14,3\%) foi muito afetada (Figura 3).

Figura 3 - Respostas atribuídas pelos respondentes das instituições pesquisadas à questão, em que escala a pandemia COVID-19 atingiu as ações/funcionamento da instituição?

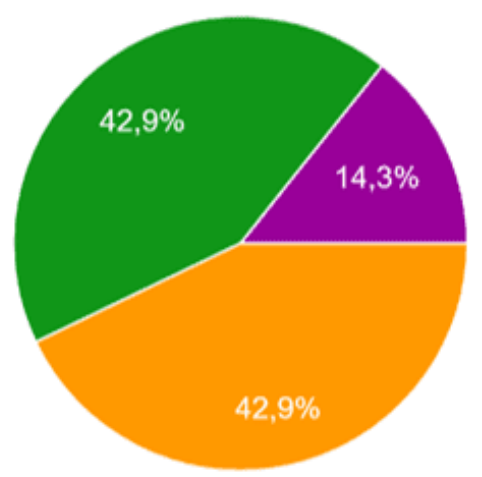

Nada afetou

Pouco afetou

Afetou em mínima escala

Afetou em grande escala

Afetou muito

Fonte: Dados da Pesquisa.

Constata-se que, mesmo a realidade das UC's e ONG's da cidade de Caravelas não terem sido por total afetadas, tivemos um impacto significativamente grande perante a pandemia do COVID-19.

Nessa perspectiva, foi possível observar com relação ao número de funcionários de cada instituição pesquisada, que se obteve as seguintes respostas: 03 (42,9\%) das instituições pesquisadas não foram afetadas em nada, mantendo o número de colaboradores do período anterior a pandemia COVID-19, 02 (28,6\%) das instituições foram muito afetadas, 01 (14,3\%) instituição foi afetada em mínima escala e por fim, 01 (14,3\%) instituição foi afetada em grande escala (Figura 4).

RC: 96564

Disponível em: https://www.nucleodoconhecimento.com.br/meioambiente/instituicoes-ambientais 
Figura 4 - Respostas atribuídas pelos respondentes das instituições pesquisadas à questão, quanto a pandemia afetou no número de funcionários/as e voluntários da instituição?

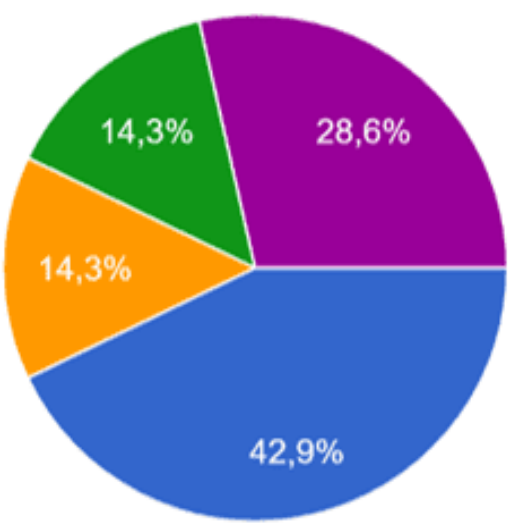

Nada afetou

Pouco afetou

Afetou em minima escala

Afetou em grande escala

Afetou muito

Fonte: Dados da Pesquisa.

Verificou-se que, nesse mesmo sentido os fatores sociais e econômicos foram evidentes em relação ao número de funcionários de cada instituição, fazendo com que algumas dessas fossem afetadas, levando a redução do número de contribuintes.

Os cidadãos começam a sentir os efeitos deletérios do Coronavírus na economia e no mercado de trabalho. O isolamento social, como medida necessária à contenção desse contagioso vírus, apesar de imperioso, produz consequências danosas e de grandes proporções, já sendo possível identificar no Brasil as primeiras manifestações dessa desordem social. (MARTINEZ et al, 2020, p. 12).

Conforme pode-se observar na Figura 5 , as instituições através dos seus respondentes foram questionadas com relação ao impacto que tiveram referente a pandemia COVID-19 em suas Políticas Públicas Ambientais direta ou indiretamente no seu Plano de Manejo dentro dos princípios de ação do poder? Em números obteve-se $05(71,4 \%)$ instituições apresentaram impacto em grande escala, 01 $(14,3 \%)$ foi afetada em mínima escala e 01 (14,3\%) das instituições que foi afetada em grande escala.

RC: 96564

Disponível em: https://www.nucleodoconhecimento.com.br/meioambiente/instituicoes-ambientais 
Figura 5 - Respostas atribuídas pelos respondentes das instituições pesquisadas quanto à questão, a pandemia impactou direta ou indiretamente na criação e elaboração de Políticas Públicas Ambientais?

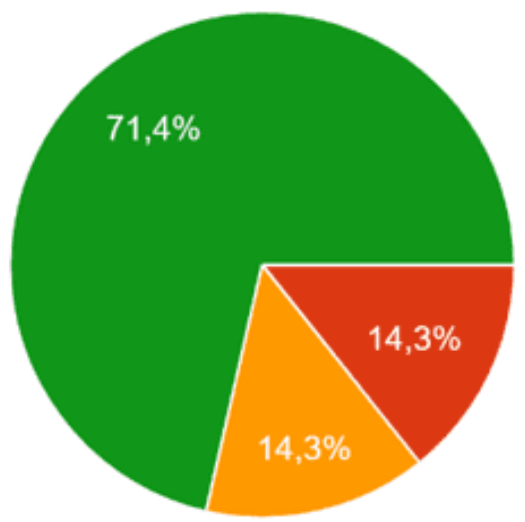

Nada afetou

Pouco afetou

Afetou em mínima escala

Afetou em grande escala

Afetou muito

Fonte: Dados da Pesquisa.

Maglio (2000), aborda sobre a importância social que a gestão ambiental no setor público tem, onde por sua vez estão associadas à implementação da política ambiental pelos governos. Nesse momento de pandemia falta então recursos técnicos, financeiros e estruturais para seguir com os trabalhos realizados anualmente pelas instituições.

Constatou-se que, no período da realização da presente pesquisa das 07 instituições pesquisadas, 02 instituições não retornaram ainda as suas atividades, porém 05 já retornaram suas atividades. Sendo que, 02 (40\%) das instituições se disseram afetadas em grande escala, $02(40 \%)$ foram afetadas em mínima escala e apenas uma (20\%) disse que foi pouca afetada (Figura 6 ).

Figura 6 - Respostas atribuídas pelos respondentes das instituições pesquisadas quanto à questão, sua instituição nesse momento atual já retomou suas atividades, em que escala encontra-se o funcionamento/ações da instituição após sua reabertura? 


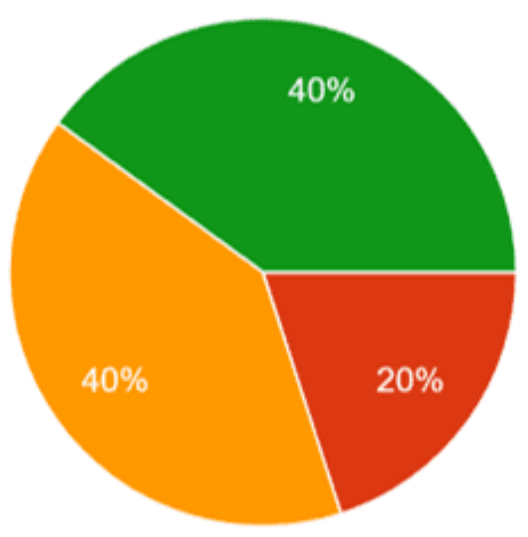

Nada afetou

Pouco afetou

Afetou em mínima escala

Afetou em grande escala

Afetou muito

Fonte: Dados da Pesquisa.

Com relação aos dados anteriormente apresentados, nota-se que a Pandemia do COVID-19 trouxe impactos para o funcionamento das instituições pesquisadas, com $40 \%$ afirmando que houve impactos entre a escala mínima e grande escala, onde elas estão sendo obrigadas a se reinventar a cada dia para que o seu trabalho não pare.

\section{CONSIDERAÇÕES FINAIS}

Conclui-se ao se analisar os impactos e desafios impostos pela pandemia da COVID-19 no desempenho das atividades e ações das UC's e ONG's que atuam na conservação e preservação do meio ambiente na cidade de Caravelas, Bahia que:

- Verificou-se que em decorrência da pandemia, houve desemprego, fechamento de escritório, atividades de campo paralisadas e cancelamento de eventos.

- As atividades não deixaram de serem realizadas e sim adaptadas para serem desenvolvidas nesse momento súbito de maneira remota. Parece acertado declarar que se trata de uma nova configuração de trabalho, mas não definitiva, fazendo uso provavelmente exagerado da tecnologia; 
- Nota-se que, a pandemia afetou em grande escala essas instituições ambientais pesquisadas e as suas ações que eram realizadas antes da pandemia presenciais tiveram que ser adaptadas ou foram suspensas.

- Espera-se que a pandemia da COVID-19 possa conduzir ao repensar sobre as ações antrópicas ao meio ambiente e de como tais ações nos afeta seres humanos e o Planeta.

Por fim, ainda é cedo para se afirmar que a pandemia da COVID-19 desencadeou impactos desastrosos ao meio ambiente em Caravelas/Bahia, nota-se evidências nas mudanças de dinâmicas ambientais, sobretudo houve preservação e avanço em alguns setores, como a pesca. Mas, houve impactos negativos quanto à criação e elaboração de políticas públicas ambientais pelas instituições pesquisadas.

Assim, evidencia-se a necessidade de acompanhamento contínuo nas UC's e ONG's ambientalistas de Caravelas, no contexto de transição das atividades realizadas atualmente de forma remota para a sua volta ao presencial, com adoção de estratégias de construção participativa entre o terceiro setor, setor público e sociedade civil.

\section{REFERÊNCIAS}

AGÊNCIA NACIONAL DE VIGILÂNCIA SANITÁRIA (ANVISA). Nota técnica $n$. 05/2020 GVIMS/GGTES. Orientações para a Prevenção e Controle de Infecções pelo novo coronavírus (SARS-Cov-2) em Instituições de Longa Permanência para Idosos (ILPI). Brasília, 2020.

ANDRADE, A. C. S.; DOMINGUEZ, J. M. L. Informações geológicogeomorfológicas como subsídios à análise ambiental: o exemplo da planície costeira de caravelas - Bahia. Boletim Paranaense de Geociências, Pará, n. 51, p. 9-17, 2002. 
BECHING, N.; FLETCHER, T.; ROBERT, F.; COVID-19. BMJ Best Pract. 2020; Lastupdated, 2020.

BEZZERA, et al. Fatores associados ao comportamento da população durante o isolamento social na pandemia de COVID-19. Ciência \& Saúde Coletiva 25, 05 Jun 2020.

BRAZ, M.V.A. pandemia de covid-19 (sars-cov-2) e as contradições do mundo do trabalho. R. Laborativa, v. 9, n. 1, p. 116-130, abr./2020.a

BRITO, et al. Pandemia da COVID -19: o maior desafio do século XXI. Vigil. Sanit. Debate 2020; 8(2):54-63.

BRUNETTI, E, A. A. A PANDEMIA: Home office, conferences e os desafios profissionais. Revista de Ubiquidade, v. 3, n. 2, p. 51-60, 2020.

CHENEN.; et al. Epidemiologicalandclinicalcharacteristicsof 99 cases of 2019 novel coronavirus pneumonia in Wuhan, China: a descriptivestudy. The Lancet. 2020.

DASA ANALYTICS. Dados COVID-19. Disponível em: https://dadoscoronavirus.dasa.com.br/. Acesso em: 12 abril, 2021.

DUTRA, L. X. C. Os efeitos do aporte de sedimento na vitalidade dos recifes da região de Abrolhos, Bahia. 2003. 84 f. (Dissertação de Mestrado). Instituto de Geociências, Universidade Federal da Bahia, Salvador, 2003.

FONSECA, J. J. S. Metodologia da pesquisa científica. Fortaleza: UEC, 2002. Apostila.

GIL, A. C. Como elaborar projetos de pesquisa. 4. ed. São Paulo: Atlas, 2002.

GUENTHER, M. Como será o amanhã? O mundo pós-pandemia. Revista Brasileira De Educação Ambiental (RevBEA), v. 15, n. 4, p. 31-44, 2020. 
HENRIQUES, C. M. P.; VASCONCELOS, W. Crise dentro da crise: respostas, incertezas e desencontros no combate á pandemia da COVID-19 no Brasil. Estudos avançados 34 (99), 2020.

IBGE. Instituto Brasileiro de Geografia e Estatística, 2017.Caravelas (BA). Disponível em: <https://cidades.ibge.gov.br/brasil/ba/caravelas $\geq$. Acesso em: 14 fev. 2021.

INEMA - Instituto do Meio Ambiente e Recursos Hídricos, Caravelas (BA), 1993.Disponível em: < www.inema.ba.gov.br>. Acesso em: 14 fev. 2021.

MAIA, C. M.; et al. Isolamento social muda a dinâmica do meio ambiente durante a pandemia.Revista eletrônica de jornalismo cientifico.2020. Disponível em: <https://www.comciencia.br/isolamento-social-muda-a-dinamica-do-meioambiente-durante-a-pandemia/z. Acessoem: 14 fev. 2021.

MAGLIO, I. C. A descentralização da gestão ambiental no Brasil: o papel dos órgãos estaduais e as relações com o poder local, 1900/1999. 2000. Dissertação (Mestrado em Saúde Pública) - Faculdade de Saúde Pública da Universidade de São Paulo, São Paulo.

MARQUES, P. H. D; ; Entre territorialidades da pesca artesanal no maretório de Caravelas e Nova Viçosa-BA. GeoTextos, vol. 16, n. 1, julho 2020. P. Marques. 6383.

MARTINEZ, L; POSSIDIO, Cyntia. O trabalho nos tempos de Coronavirus. São Paulo: Saraiva Educação, 2020.

OLIVEIRA, M. S. C.; SIQUEIRA, T. D. A. Coronavírus: globalização e seus reflexos no meio ambiente. BIUS-Boletim Informativo Unimotrisaúde em Sociogerontologia, v. 20, n. 14, p. 1-12, 2020. 
Prefeitura Municipal de Caravelas (PMC). Combate ao Coronavírus. Disponível em: https://www.caravelas.ba.gov.br/. Acesso em: 12 abril, 2021.

SANTOS, B. S. A cruel Pedagogia do Vírus. ISBN 978-972-40-8496-1, CDU 347. 2020.

Secretaria de Saúde da Bahia (SESAB). Bahia confirma primeiro caso importado do Novo Coronavírus (Covid-19). Disponível em: aude.ba.gov.br/2020/03/06/bahiaconfirma-primeiro-caso-importado-do-novo-coronavirus-covid-19/. Acesso em: 14 fevereiro, 2021.

SECRETARIA DE SAÚDE DO ESTADO DA BAHIA (SASEB). Boletins Diários, COVID-19.

Disponível

em:

http://www.saude.ba.gov.br/temasdesaude/coronavirus/boletins-diarios-covid-19/. Acesso em: 12 abril, 2021.

SOUZA, L.P. (2020). A pandemia da COVID-19 e os reflexos na relação meio ambiente e sociedade.Revista Brasileira de Meio Ambiente, v.8, n.4, p.68-73.

SULBAHIA NEWS. Caravelas e banco discutem parceria para geração de emprego e renda. Disponível em: https://www.sulbahianews.com.br/caravelas-ebanco-do-nordeste-discutem-parceria-para-a-geracao-de-emprego-e-renda/. Acesso em: 19 fevereiro, 2021.

WERNECK, G. L.; CARVALHO, M. S.; A pandemia de COVID-19 no Brasil: crônica de uma crise sanitária anunciada. Cad. Saúde Pública 2020; 36(5):e00068820.

Enviado: Abril, 2021.

Aprovado: Setembro, 2021. 